\title{
Mining Engineer Competencies for an Innovative Economy
}

\author{
Anna Barbara $^{1, *}$, and Peter Tauš ${ }^{2}$ \\ ${ }^{1}$ T.F. Gorbachev Kuzbass State Technical University, Mezhdurechensk Branch, 652881 \\ Mezhdurechensk, 36 Stroiteley st., Russian Federation \\ ${ }^{2}$ Technical University Košice, Faculty BERG, Letná 9, 04001 Košice, Slovakia
}

\begin{abstract}
One of the features of modern mining is its focus on the development of human resources. The high level of labor productivity, as the main factor in the efficiency of mining enterprises in the context of heightened competition in the mineral resources market, brings to the fore the assessment of the state of human potential and its use with maximum efficiency. Consequently, the successful operations of a mining enterprise largely depend on how effectively its human potential is used. To achieve high results of work, a competently built personnel policy is required, one of the key tasks of which is the selection and placement of personnel. As practice shows, the shortage of qualified mining engineers and the growth of their cost in the labor market can become one of the key factors hindering the development of business in the field of mining.
\end{abstract}

\section{Introduction}

Kemerovo Region-Kuzbass is one of the developed industrial regions of the Russian Federation. The leading industry in Kuzbass is mining, and the Kuznetsk coal basin is the largest national supplier of coal. In terms of coal reserves and quality, the Kuznetsk coal basin (Kuzbass) is the largest of all the exploited basins in the world. In a small area of 26.7 thousand square kilometers, rich deposits of various grades of coal are concentrated, for a very wide range of use: for coke and liquid fuel production, electric energy, and for the chemical industry. There are no coal deposits similar to Kuzbass in the world [1].

Currently, the coal industry is going through a stage of modernization and technical reequipment, the creation of new competitive industries. However, along with this, there is an acute shortage of qualified personnel, especially mining engineers, in light of which the issues of human resources development are especially relevant. The development and improvement of the efficiency of using the human potential of the energy sector is declared in the Energy Strategy of Russia for the period up to 2030 as one of the main problems in this area [2]

It is difficult to overestimate the importance of engineers and technicians in supporting the production processes of coal mining enterprises. They are entrusted with performing a large number of responsible functions. These include the development and implementation

* Corresponding author: barbara_ad@mail.ru 
of production processes and modes, setting the order of work and the sequence of performing labor operations, determining the main methods of quality control, maintaining technical documentation. In addition, mining engineers work with a large amount of heterogeneous information (diagrams, graphs, programs, reports), which must be analyzed, structured and used in building effective communications in the production team.

\section{Materials and Methods}

As a case study, the authors consider the existing requirements, as well as the models for the selection and assessment of personnel, the use of these technologies in the mining industry. The relevance of a high-quality recruitment of engineers is high, since a lot depends on the managerial and technical decisions of engineer expert.

In connection with the multifactorial activity of engineering and technical employees, the problem of selection and assessment of personnel that meets the requirements of employers becomes urgent. Most of the existing models for the selection and assessment of personnel for the mining industry do not meet modern requirements, since when conducting an assessment it is important to take into account all aspects characterizing an employee: personal qualities, professional skills, health status, and in the conditions of technological progress and the age of information technology - the ability to training and continuous selfimprovement. High demand is placed on professionalism, managerial skills, the ability to work with people, the ability to make decisions in critical situations, to act effectively in conditions of uncertainty, personal qualities and psychological state of an engineer.

\section{Results and Discussion}

Traditionally, it is believed that the search and selection of personnel is a function of personnel services. Note that for effective recruitment, the participation of department heads is necessary, because they, like no one else, understand what requirements a newly hired employee must meet. This entails that managers are aware of the basic selection techniques and processes. The managers of the enterprises pay more and more attention to the qualitative characteristics of the personnel. The quality of labor resources, their contribution to the achievement of the goals of organizations directly depends on how competently the processes for the selection of personnel are established.

It is worth paying attention to the role and place of the organization's employees in the economic security system, since one of its components is personnel security. Since human resources in any of the components of economic security are primary, it is precisely personnel security that needs to be given increased attention, therefore, it is necessary to approach the procedures for the selection and placement of personnel more carefully.

By personnel security we mean the process of eliminating or reducing risks and threats associated with personnel and, as a result, preventing negative impacts on the economic security of enterprises. The main risk factors include the following: insufficient qualifications of employees, poorly built personnel management system, absent or ineffective motivational policy, poor-quality recruitment.

When selecting personnel, a variety of methods are used, the most common among them are tests, interviews and assessment centers [3, 4]. Let us consider each method in more detail.

1. Tests. The main types of tests, first of all, include the analysis of personal data and resume of applicants, psychological testing. Personal data and characteristics allow the selection specialist to make an assumption about the professional qualifications and skill of 
the candidate, the individual psychological characteristics of the applicant. However, hypotheses need to be supported by the results of other types of assessment, such as testing.

The most popular assessment method among employers continues to be psychological testing, not only due to its high validity, but also due to good standardization and automation of the testing procedure. In addition, the use of test methods almost completely eliminates the subjective component of personnel selection. The capabilities of the tests are very limited, since psycho-diagnostics is reduced to the study of those qualities for which the appropriate instrumentation has been developed. It is possible to solve this problem by using batteries of tests, which will expand the range of assessed qualities, but this will entail a significant investment of time and labor resources.

2. The assessment center is a complex (combined) method, characterized by the fact that it allows not only to combine various assessment methods (interviewing, observation, testing, group and individual exercises, various forms of diagnostic business games, etc.), but also to combine the efforts of various subjects of assessment and selection of personnel (managers of various levels, representatives of the personnel department, psychologists, etc.)

A characteristic feature of this method is that the assessment of the professionally important qualities of applicants is carried out in artificially created situations that reflect the key points of a specific activity. The main subjects of the assessment and selection of personnel, in this case, are the future managers of the candidate, with a certain level of training. Despite all the advantages of the Assessment Center method - its organization and implementation - is a rather laborious business and requires significant time and material costs.

3. Interview. One of the most productive assessment methods that does not require significant labor costs and is available to a wide range of specialists. Despite its obvious advantages, there are a number of disadvantages - this is the subjectivity of the assessment, the presence of special training for conducting an interview, the prevalence of the external (first) impression of the employee over the content of the conversation.

The study made it possible to identify the basic requirements for the special competence of engineers at mining enterprises. The list of requirements is given below:

- Knowledge of the regulatory framework,

- Knowledge of the technological process,

- Knowledge of mining equipment,

- Knowledge of support technology and equipment,

- Knowledge and ability to use technical documentation,

- Knowledge of the complete production cycle,

- Understanding the strategic goals and objectives of the company,

- Ability to work in automated document management systems,

- Willingness to introduce new technologies, innovation,

- Ability to work in design programs according to specialization,

- Knowledge of modern innovative mining technologies,

- Knowledge of the theoretical foundations of team management,

- Proficiency in a foreign professional language.

In today's rapidly changing and increasingly complex world, there is an endless increase in knowledge, professions are changing, and with them competencies are becoming obsolete. The increasing complexity of production tasks requires a change in the methods of their solution, constant improvement. All this indicates the need for a transdisciplinary approach, both in solving industrial problems and in organizing educational activities, and conducting scientific research [6, 7]. In turn, mining education system is required to revise educational programs in such a way that, in addition to professional and special competencies, 
transversal competences are also formed. For example, for mining engineers T. Dorydina [8] identifies the Top 10 competences:

1. Ability to make decisions in a difficult unexpected situation.

2. Ability to cope with difficulties.

3. Efficiency in decision making.

4. Strategic and innovative thinking.

5. Adaptability.

6. IT competencies.

7. Communication skills.

8. Skills of information processing and analysis.

9. Reflexive thinking.

10. Linguistic and cultural competence.

These results indicate that there is a need to rethink and redefine the requirements for employees and the conduct of work in general. Complicating reality, the growing demands of stakeholders require mining companies to change their strategy of work, as existing practices no longer meet the requirements of economic growth and social efficiency. The key themes for changing the operational management strategy and technology support are the following [9-12]:

Well-being. Improving working conditions, including through informatization and digitalization. Already, security systems make it possible to accurately determine the location of workers and mechanisms, monitor the safe conduct of mining operations, prevent dangerous situations; unmanned vehicles are used at open pits and in mines. Further development of technologies will be aimed at replacing human labor at the most dangerous stages of mining, broad digital transformation and intelligent mining [11].

Leadership in the digital age is a broad organizational transformation, from interaction with staff and business units, to changing the way decisions are made and the optimal use of resources. The use of artificial intelligence and machine learning requires the development of new skills in order to build a flexible and adaptive digital environment and to understand that the rate of growth depends more on intellectual capital than on technology. Mining companies need to analyze their readiness for this kind of change at all levels. There are opinions that leadership can be achieved by adhering to the strategy of diversity and integration [9]. This requires the development of mentoring, inclusion in terms of the parameters and characteristics of mining equipment and cooperation with the academic and scientific communities in order to speed-up the development of mining sector.

Added reality (AI), robotics and automation. We can say that the mining industry is one of the leaders in the implementation of these technologies [9]. For example, unmanned dump trucks or added reality technologies when carrying out maintenance, in warehouse logistics [13] or when training technical personnel, the use of digital twins [12]. Effective use of these technologies requires a completely different set of competencies and this task has not yet been solved. According to Deloitte [9], only $31 \%$ of engineers consider themselves ready for such changes. Digital transformation of production opens up broad prospects for ensuring melon-based management, introducing game methods in personnel and productivity management, using artificial intelligence and augmented reality in equipment maintenance, troubleshooting, predictive maintenance, and increasing the operational value of the field.

Social and social impact. The competitiveness of a business depends on the well-being of the society in which it operates. Creation of Shared Value (CSV) concept addresses critical social issues and, therefore, enables companies to grow. There is a close relationship between social well-being and growth of enterprises. For example, the low level of development of education and health systems, on the one hand, leads to a shortage 
of qualified labor for companies, on the other hand, to a high level of unemployment. Social programs can become one of the competitive advantages of enterprises in attracting labor force. There is no doubt that companies that create shared values will be more attractive for young people, which, as a result, will contribute to the replenishment of personnel and an increase in labor productivity. According to a Deloitte study, young people working in socially oriented companies are twice as motivated to work [14]. Increasingly, companies are basing their business strategy on social issues, solving several problems at once.

Changing requirements for employees entails the modernization of the system of training specialists, with the competencies set to solve the problems of Industry 4.0, such as systems thinking, inter-industry communication, project management, IT competencies, customer focus, teamwork skills, the ability to act in conditions of uncertainty, multiculturalism, awareness, communication skills. As globalization and rapid advances in technology continue to transform civic space and the world of work, education systems are becoming increasingly distanced from the reality and needs of global economies and societies. Educational models must adapt in order to equip skills to create a more inclusive, cohesive and productive world.

The report Schools of the Future Defining New Models of Education for the Fourth Industrial Revolution [15] identifies eight critical characteristics for learning content:

1. Global citizenship skills include everything related to raising awareness of the "big" world, resilience and active role in the global community.

2. Skills for innovation and creativity include everything related to the development of skills necessary for innovation, including complex problem solving, analytical thinking, creativity and systems analysis.

3. Technological skills, includes everything that is aimed at developing digital skills, including programming, digital responsibility and the use of technology.

4. Interpersonal skills include everything about interpersonal emotional intelligence, including empathy, collaboration, negotiation, leadership and social responsibility.

5. Individual and independent training. Moving from a system in which learning is standardized to a system based on the diverse individual needs of each student, and flexible enough to allow each student to progress at their own pace.

6. Accessible and inclusive education. Moving from a system in which learning is limited to those who have access to school buildings to a system in which everyone has access to learning and therefore the system is inclusive.

7. Problematic and collaborative learning. Transition from a process-based learning paradigm to a project-based one that requires equal cooperation and an accurate representation of future work.

8. Lifelong and student-centered learning. The transition from a system in which learning and skills decline throughout life, to a system in which everyone constantly improves existing skills and acquires new ones in accordance with their individual needs.

From the foregoing, we can conclude that the results of our study to determine the most important competencies for engineers in general correlate with global trends.

\section{Conclusion}

Building an innovative economy and improving the quality of life is impossible without investment in human capital. In modern economic conditions, the problem of effective use of human capital is put forward as a priority task. When it comes to the coal mining industry, coal plays a crucial role in global energy growth. The demand for coal is constantly growing, and an increasing percentage of the world's electricity is dependent on power plants that use this resource. Despite the huge distribution of coal reserves around 
the world, these volumes are not enough. In addition, the environmental harm resulting from mining activities is a serious issue, and therefore it is imperative to introduce innovative technologies to improve mining and coal processing, while taking into account the efficiency and importance of environmental sustainability. Even the transition of developed countries, mainly the European Union, to green energy will not stop the growth of coal markets, since overall demand will grow at the expense of developing countries; by 2040 , the projected growth is more than $25 \%$ [16]. It is imperative to find long-term technological and organizational solutions that will take the coal sector to the next level and enable a better response to future global challenges.

\section{References}

1. Kemerovo region investment passport (Kemerovo Region State Public institutions "Agency for Investments Promotion and Protection", Kemerovo, 2018)

2. Energy Strategy of Russia for the period up to 2030 (Institute of Energy Strategy, Moscow, 2010)

3. Five Most Used HR Assessment Methods in 2020. URL: https://www.talentlyft.com/en/blog/article/370/5-most-used-hr-assessment-methods-in2020

4. E.D. Pulakos, Selection Assessment Methods. A guide to implementing formal assessments to build a high-quality workforce (SHRM Foundation, Berlin, 2005)

5. S.L. Rynes, A.E. Colbert, K.G. Brown, Human Resource Management, 41, 149-174 (2002)

6. World Declaration on Higher Education for the Twenty-First Century: Vision and Action (World Conference on Higher Education, Chicago, 1998)

7. American Academy of Arts and Sciences, ARISE II-2013. URL: https://www.amacad.org/multimedia/pdfs/publications/researchpapersmonograph/arise 2.pdf

8. T. Dorydina, N. Kersh, V. Kononova, T. Shipilova, N. Usvyat, E3S Web Conf. 105, 04032 (2019).

9. Beyond HR: Rethinking work and operations in the mining industry (Deloitte, New York, 2018)

10. Deloitte Global Human Capital Trends Mining \& Metals Perspective (Deloitte, New York, 2019)

11. Intelligent Mining: Delivering Real Value (Deloitte, New York, 2018)

12. A. Parrott, L. Warshaw, Industry 4.0 and the Digital Twin (Deloitte Insights, New York, 2017)

13. E.K. Rodnichenko, IOP Conf. Ser.: Earth Environ. Sci., 688, 012008 (2021)

14. N. Andersen, T. Murphy, A. Börsch, Deloitte Review, 18, 70-85 (2016)

15. WEF, Schools of the Future Defining New Models of Education for the Fourth Industrial Revolution-2019. URL: http://www3.weforum.org/docs/WEF_Schools_of_the_Future_Report_2019.pdf

16. WEO 2018 (Analisys IEA, Boston, 201) 